\title{
Technological and nutritional aspects of milk chocolate enriched with grape pomace products
}

\author{
Siegfried Bolenz ${ }^{1} \cdot$ Laura Glöde $^{1}$
}

Received: 18 August 2020 / Revised: 2 November 2020 / Accepted: 7 November 2020 / Published online: 8 December 2020

(c) The Author(s) 2020

\begin{abstract}
The French paradox is the observation of low heart disease death rates despite high intake of cholesterol and saturated fat, possibly related to the consumption of red wine containing polyphenols. Those are also found in pomace and affect health as radical catchers inhibiting cancer, inflammations and arteriosclerosis. European cocoa regulation allows incorporating up to $40 \%$ of added foodstuffs into chocolate, so grape pomace can be used. Cocoa itself is known as a very good source of phenolic compounds, and consequently dark chocolate is considered to have similar health benefits as red wine. Milk chocolates contain only little fat-free cocoa dry matter; therefore, grape pomace is considered most beneficial here. Entire pomace or flour from seeds have been tested to evaluate technical aspects as well as the impact on chocolate properties like particle size distribution, flow properties, total phenol content, antioxidative capacity and sensory perception. Initial trials revealed that additional drying and also pre-grinding was necessary before pomace can be used as an ingredient. Various samples were produced by the coarse conching process, which uses a ball mill for size reduction below $30 \mu \mathrm{m}$. A difficulty arises when some tough particles slip through without being properly ground; D99-values can be used to better control this issue. Grape pomace contains almost as many polyphenols as cocoa liquor, so it can serve as a substitute. Its content and thus quality depends on gentle drying. Finally, adding, e.g., just 3.5\% was able to significantly increase the polyphenol contents of milk chocolate.
\end{abstract}

Keywords Milk chocolate $\cdot$ Grape pomace $\cdot$ Grape seeds $\cdot$ Polyphenols $\cdot$ Antioxidative capacity $\cdot$ Health benefits $\cdot$ Particle size $\cdot$ Flow properties $\cdot$ Sensory perception

\section{Introduction}

During the winemaking 20-30\% of waste material accrue of grape pomace including skins, seeds and stems. The European wine Industry produces four million tonnes of grape pomace per year [1].

As explained by Sun et al. [2], the French paradox is the observation of low heart disease death rates despite high intake of cholesterol and saturated fat. Hypotheses relate this to the consumption of red wine and its content of polyphenols derived from grape skins. According to Soto et.al. [3], Matissek and Baltes [4], Machado NFL and DomínguezPerles [5] substances like anthocyanins, flavonoids and

Siegfried Bolenz

bolenz@hs-nb.de

1 Hochschule Neubrandenburg-University of Applied Sciences, Brodaer Straße 2, 17033 Neubrandenburg, Germany resveratrol are found in pomace as well as in wine and affect health as radical catchers inhibiting cancer, inflammations and arteriosclerosis.

According to European cocoa regulation up to $40 \%$ of added foodstuffs can be incorporated into chocolate [6]. Thus grape pomace can be used to increase its polyphenol content and to get health benefits. Cocoa itself is known as a very good source of phenolic compounds; consequently, dark chocolates can be considered to have similar health benefits as described for red wine [4].

Milk chocolates contain less fat-free cocoa dry matter for a mild, milky taste preferred by consumers. Those products can benefit from using a less taste intense ingredient as a source of polyphenols. Other raw materials have already been considered as polyphenol rich ingredients in chocolate, e.g., cinnamon by Muhammad et al. (2018); due to its strong taste the material has be processed to an extract beforehand [7]. 
Therefore, grape pomace can be a less flavour-intense alternative. It mainly consists of peels and seeds. Dwyer et.al. [8] explain that after pressing out the juice, $70 \%$ of the polyphenols remain in the pomace. The peels are quite different from the seeds, as they contain colouring anthocyans and wine residues. Therefore both grape seed flour and grape pomace are considered as chocolate ingredients in this study. The latter is the entire product remaining after wine or juice has been pressed. After drying, grape seeds are usually obtained by sieving and then milled to flour. Beside from different pomace products, also different types of chocolate production and times of addition were compared.

Some general aspects of chocolate-making have also to be considered when aiming at a positive perception by consumers, certain taste and mouth feeling characteristics have to be achieved by ingredients and process. Particle size measured by laser diffraction should not exceed $30 \mu \mathrm{m}$; otherwise, it feels gritty [9]. "Smooth melting" is related to the flow properties of the liquid chocolate mass $[9,10]$. According to Afoakwa et.al. [11], those depend largely on the contents of fat, water and emulsifiers. Water content must be reduced to $<0.6 \%$ during production, which is considered uncritical for the final product as found out by Franke et.al. [12].

Grape pomace is a new ingredient for the chocolate industry, so technological aspects have been emphasized first. Then various types and amounts were incorporated into milk chocolate with different production methods to see its impact on properties like particle size distribution, flow properties, total phenol content, antioxidative capacity and sensory perception.

\section{Materials and methods}

\section{Experimental design}

First the different types of raw material were considered as a categorical variable. Thus, different experimental set-ups were developed for grape pomace and grape seed flour. In the coding of the trials " $\mathrm{S}$ " stands for grape seed flour (result Tables 1, 2, 3), and "P" for grape pomace (Tables 4, 5, 6). Within each set-up varying amounts of grape material were used as a continuous variable. Thus the number in the trial code indicates the amount of grape product in the recipe, including " 0 " meaning a reference sample. Superscript roman numbers indicate trial repetitions.

Second, incorporation into the conventional chocolate making process consisting of roll refining and conching [10] was considered versus using the new coarse conching process [13]. The production methods are indicated by " $\mathrm{C}$ " for conventional method while every unmarked sample was made by coarse conching.

Third, it was considered to grind the grape material together with chocolate ingredients versus to grind it separately and to add it to the final chocolate mass. The index "E" indicates the latter; when samples are not marked the grape product was added at the beginning.

Finally, processing the grape raw material before adding it to chocolate needed to be adjusted due to its varying properties. These steps were also varied based on some learning during the project. The grape seed flour was not pre-ground in the trials $3.5 \mathrm{~S}^{\mathrm{I}}, 3.5 \mathrm{~S}^{\mathrm{II}}, 5 \mathrm{~S}^{\mathrm{II}}$, $7 \mathrm{~S}$ and $10 \mathrm{~S}$. For the trials $3.5 \mathrm{~S}^{\mathrm{III}}, 5 \mathrm{~S}^{\mathrm{I}}, 5 \mathrm{~S}_{\mathrm{E}}^{\mathrm{I}}$ and $5 \mathrm{~S}_{\mathrm{E}}^{\mathrm{II}}$ the seed flour was pre-grinded in the ball mill mixed with cocoa butter $(1: 1)$. Whenever mixtures of grape product and cocoa butter

Table 1 Mean values and standard deviation for specific surface, span, specific width, particle size of chocolates with grape seed flour processed by coarse conching with different times of addition

\begin{tabular}{|c|c|c|c|c|c|c|c|c|}
\hline Trial & $\begin{array}{l}\text { Seed flour } \\
\text { pre-ground }\end{array}$ & $\begin{array}{l}\text { Specific surface } \\
\left(\mathrm{m}^{2} / \mathrm{g}\right)\end{array}$ & Span & Specific width & $\mathrm{X} 10(\mu \mathrm{m})$ & $\mathrm{X} 50(\mu \mathrm{m})$ & $\mathrm{X} 90(\mu \mathrm{m})$ & X99 $(\mu \mathrm{m})$ \\
\hline oS & - & $0.981^{\mathrm{CD}} \pm 0.025$ & $2.321^{\mathbf{D}} \pm 0.052$ & $7.537^{\mathbf{D}} \pm 0.125$ & $2.946^{\mathbf{A}} \pm 0.058$ & $8.296^{\mathrm{B}} \pm 0.194$ & $22.194^{\mathrm{CD}} \pm 0.262$ & $35.993^{\mathrm{ABC}} \pm 1.161$ \\
\hline $3.5 \mathrm{~S}^{\mathrm{I}}$ & No & $1.058^{\mathrm{A}} \pm 0.009$ & $2.441^{\mathbf{B C D}} \pm 0.058$ & $8.401^{\mathrm{BC}} \pm 0.198$ & $2.659^{\mathrm{B}} \pm 0.013$ & $8.063^{\mathrm{B}} \pm 0.068$ & $22.340^{\mathbf{C D}} \pm 0.619$ & $31.937^{\mathbf{B C}} \pm 1.619$ \\
\hline $3.5 \mathrm{~S}^{\mathrm{II}}$ & No & $1.057^{\mathbf{A B}} \pm 0.011$ & $2.384^{\mathrm{CD}} \pm 0.107$ & $8.227^{\mathbf{B C}} \pm 0.403$ & $2.670^{\mathbf{B}} \pm 0.019$ & $8.089^{\mathrm{B}} \pm 0.109$ & $21.966^{\mathrm{CD}} \pm 1.084$ & $31.270^{\mathbf{B C}} \pm 1.978$ \\
\hline $5 S^{I I}$ & No & $1.065^{\mathbf{A}} \pm 0.020$ & $2.557^{\mathbf{A B}} \pm 0.063$ & $8.653^{\mathbf{A B}} \pm 0.286$ & $2.652^{\mathrm{B}} \pm 0.057$ & $7.936^{\mathrm{B}} \pm 0.200$ & $22.950^{\mathbf{B C D}} \pm 0.958$ & $34.115^{\mathbf{A B C}} \pm 1.538$ \\
\hline $7 \mathrm{~S}$ & No & $1.047^{\mathrm{AB}} \pm 0.011$ & $2.431^{\mathbf{B C D}} \pm 0.037$ & $8.406^{\mathrm{BC}} \pm 0.212$ & $2.695^{\mathbf{B}} \pm 0.012$ & $8.209^{\mathrm{B}} \pm 0.141$ & $22.658^{\mathrm{CD}} \pm 0.653$ & $32.230^{\mathbf{B C}} \pm 0.571$ \\
\hline $10 \mathrm{~S}$ & No & $1.031^{\mathrm{ABC}} \pm 0.029$ & $2.650^{\mathbf{A}} \pm 0.073$ & $9.068^{\mathbf{A}} \pm 0.226$ & $2.700^{\mathbf{B}} \pm 0.095$ & $8.218^{\mathrm{B}} \pm 0.248$ & $24.468^{\mathbf{A B}} \pm 0.654$ & $37.125^{\mathbf{A B}} \pm 2.819$ \\
\hline $3.5 \mathrm{~S}^{\mathrm{III}}$ & Yes & $1.035^{\mathrm{ABC}} \pm 0.042$ & $2.391^{\mathrm{CD}} \pm 0.087$ & $8.013^{\mathrm{CD}} \pm 0.162$ & $2.760^{\mathbf{A}} \pm 0.132$ & $8.093^{\mathrm{B}} \pm 0.226$ & $22.130^{\mathbf{C D}} \pm 1.352$ & $34.920^{\mathbf{A B C}} \pm 5.572$ \\
\hline $5 S^{I}$ & Yes & $0.959^{\mathbf{D}} \pm 0.036$ & $2.482^{\mathbf{B C}} \pm 0.060$ & $8.410^{\mathbf{B C}} \pm 0.540$ & $2.964^{\mathbf{A}} \pm 0.151$ & $8.823^{\mathrm{A}} \pm 0.357$ & $24.861^{\mathbf{A}} \pm 0.943$ & $38.118^{\mathbf{A}} \pm 2.710$ \\
\hline $5 \mathrm{~S}_{\mathrm{E}}^{\mathrm{I}}$ & Yes & $1.045^{\mathbf{A B}} \pm 0.039$ & $2.344^{\mathbf{D}} \pm 0.006$ & $7.876^{\mathbf{C D}} \pm 0.218$ & $2.742^{\mathbf{B}} \pm 0.137$ & $8.033^{\mathrm{B}} \pm 0.169$ & $21.569^{\mathbf{D}} \pm 0.484$ & $32.065^{\mathrm{BC}} \pm 1.974$ \\
\hline $5 \mathrm{~S}_{\mathrm{E}}^{\mathrm{II}}$ & Yes & $1.002^{\mathbf{B C D}} \pm 0.022$ & $2.357^{\mathrm{CD}} \pm 0.009$ & $8.391^{\mathbf{B C}} \pm 0.189$ & $2.793^{\mathbf{A B}} \pm 0.037$ & $8.761^{\mathrm{A}} \pm 0.310$ & $23.443^{\mathrm{ABC}} \pm 0.841$ & $32.653^{\mathbf{B C}} \pm 1.212$ \\
\hline
\end{tabular}

Superscript indices show samples to be significantly different at $\alpha<0.05$ according to Tukey-test

$S$ grape seed flour, $E$ addition at the end of the production, number ration of grape product 
Table 2 Mean values and standard deviation for flow property descriptors of chocolates with grape seed flour processed by coarse conching with different times of addition

\begin{tabular}{llrlrlll}
\hline Trial & $\begin{array}{l}\text { Seed flour } \\
\text { pre-ground }\end{array}$ & $\begin{array}{l}\text { Casson yield value } \\
(\mathrm{Pa})\end{array}$ & $\begin{array}{l}\text { Casson viscosity } \\
(\mathrm{Pa} \mathrm{s})\end{array}$ & $\begin{array}{l}\text { Shear stress at } \\
0.05 \mathrm{~s}^{-1}(\mathrm{~Pa})\end{array}$ & $\begin{array}{l}\text { Shear stress at } \\
5 \mathrm{~s}^{-1}(\mathrm{~Pa})\end{array}$ & $\begin{array}{l}\text { Shear stress at } \\
40 \mathrm{~s}^{-1}(\mathrm{~Pa})\end{array}$ & $\begin{array}{l}\text { Viscosity at } 40 \mathrm{~s}^{-1} \\
(\mathrm{~Pa} \mathrm{~s})\end{array}$ \\
\hline $0 \mathrm{~S}$ & - & $13.443^{\mathbf{B C D}} \pm 0.489$ & $3.537^{\mathbf{C D}} \pm 0.068$ & $11.970^{\mathbf{B}} \pm 0.491$ & $69.437^{\mathbf{C}} \pm 0.574$ & $237.967^{\mathrm{D}} \pm 2.287$ & $5.952^{\mathbf{D}} \pm 0.057$ \\
$3.5 \mathrm{~S}^{\mathrm{I}}$ & No & $11.321^{\mathbf{E F}} \pm 0.278$ & $3.539^{\mathbf{C D}} \pm 0.020$ & $10.518^{\mathbf{E}} \pm 0.387$ & $63.623^{\mathbf{F}} \pm 0.328$ & $229.900^{\mathrm{F}} \pm 1.955$ & $5.749^{\mathbf{F}} \pm 0.047$ \\
$3.5 \mathrm{~S}^{\mathrm{II}}$ & No & $13.546^{\mathbf{B}} \pm 0.854$ & $3.455^{\mathbf{D}} \pm 0.144$ & $14.490^{\mathbf{A}} \pm 1.733$ & $65.340^{\mathbf{E}} \pm 3.865$ & $238.333^{\mathrm{D}} \pm 4.621$ & $5.960^{\mathbf{D}} \pm 0.119$ \\
$5 \mathrm{~S}^{\mathrm{II}}$ & No & $11.616^{\mathbf{E F}} \pm 0.220$ & $3.702^{\mathbf{C}} \pm 0.009$ & $11.403^{\mathbf{C D}} \pm 0.439$ & $64.433^{\mathbf{E F}} \pm 0.553$ & $241.467^{\mathbf{C}} \pm 2.539$ & $6.036^{\mathbf{C}} \pm 0.065$ \\
$7 \mathrm{~S}$ & No & $12.091^{\mathbf{D E}} \pm 0.237$ & $4.033^{\mathbf{B}} \pm 0.046$ & $11.757^{\mathbf{B C}} \pm 0.393$ & $69.307^{\mathbf{C}} \pm 0.252$ & $257.800^{\mathrm{B}} \pm 1.424$ & $6.447^{\mathbf{B}} \pm 0.034$ \\
$10 \mathrm{~S}$ & No & $11.370^{\mathbf{E F}} \pm 0.043$ & $2.473^{\mathbf{F}} \pm 0.012$ & $11.260^{\mathbf{C D}} \pm 0.222$ & $49.690^{\mathbf{H}} \pm 0.213$ & $175.600^{\mathrm{H}} \pm 0.490$ & $4.393^{\mathbf{H}} \pm 0.014$ \\
$3.5 \mathrm{~S}^{\mathrm{III}}$ & Yes & $13.782^{\mathbf{B}} \pm 0.460$ & $3.485^{\mathbf{D}} \pm 0.021$ & $11.547^{\mathbf{B C}} \pm 0.523$ & $71.890^{\mathbf{B}} \pm 0.586$ & $237.900^{\mathrm{D}} \pm 3.059$ & $5.947^{\mathbf{D}} \pm 0.075$ \\
$5 \mathrm{~S}^{\mathrm{I}}$ & Yes & $10.602^{\mathbf{F}} \pm 0.147$ & $3.107^{\mathbf{E}} \pm 0.147$ & $10.943^{\mathbf{D E}} \pm 0.299$ & $54.393^{\mathbf{G}} \pm 0.321$ & $206.133^{\mathrm{G}} \pm 1.454$ & $5.152^{\mathbf{G}} \pm 0.032$ \\
$5 \mathrm{~S}_{\mathrm{E}}^{\mathrm{I}}$ & Yes & $15.491^{\mathbf{A}} \pm 0.367$ & $4.826^{\mathbf{A}} \pm 0.002$ & $14.813^{\mathbf{A}} \pm 0.512$ & $86.993^{\mathbf{A}} \pm 0.454$ & $315.200^{\mathbf{A}} \pm 2.982$ & $7.880^{\mathbf{A}} \pm 0.074$ \\
$5 S_{\mathrm{E}}^{\mathrm{II}}$ & Yes & $12.152^{\mathbf{C D E}} \pm 0.268$ & $3.578^{\mathbf{C D}} \pm 0.055$ & $10.643^{\mathbf{E}} \pm 0.301$ & $67.700^{\mathbf{D}} \pm 0.205$ & $232.933^{\mathrm{E}} \pm 1.504$ & $5.826^{\mathbf{E}} \pm 0.038$ \\
\hline
\end{tabular}

Superscript indices show samples to be significantly different at $\alpha<0.05$ according to Tukey-test

$S$ grape seed flour, $E$ addition at the end of the production, number ration of grape product

Table 3 Mean values and standard deviation for total phenol content and antioxidative capacity of chocolates with grape seed flour processed by coarse conching

\begin{tabular}{lcc}
\hline Trial & mg GAE/100 g DW & mmol Trolox/100 g DW \\
\hline GSF & $2153.961^{\mathrm{A}} \pm 253.357$ & $23.274^{\mathrm{A}} \pm 2.649$ \\
$0 \mathrm{~S}$ & $148.630^{\mathrm{BC}} \pm 3.037$ & $1.435^{\mathrm{B}} \pm 0.071$ \\
$3.5 \mathrm{~S}^{\mathrm{I}}$ & $188.834^{\mathrm{BC}} \pm 6.027$ & $2.802^{\mathrm{B}} \pm 0.375$ \\
$3.5 \mathrm{~S}^{\mathrm{II}}$ & $244.232^{\mathrm{BC}} \pm 15.414$ & $2.450^{\mathrm{B}} \pm 0.357$ \\
$3.5 \mathrm{~S}^{\mathrm{III}}$ & $142.871^{\mathrm{C}} \pm 3.854$ & $2.064^{\mathrm{B}} \pm 0.075$ \\
$5 \mathrm{~S}^{\mathrm{II}}$ & $262.833^{\mathrm{BC}} \pm 17.610$ & $2.219^{\mathrm{B}} \pm 0.135$ \\
$5 \mathrm{~S}_{\mathrm{E}}^{\mathrm{I}}$ & $290.534^{\mathrm{BC}} \pm 3.579$ & $4.667^{\mathrm{B}} \pm 1.499$ \\
$5 \mathrm{~S}_{\mathrm{E}}^{\mathrm{II}}$ & $338.145^{\mathrm{BC}} \pm 8.863$ & $3.345^{\mathrm{B}} \pm 0.282$ \\
$7 \mathrm{~S}$ & $303.988^{\mathrm{BC}} \pm 4.139$ & $2.929^{\mathrm{B}} \pm 0.084$ \\
$10 \mathrm{~S}$ & $577.775^{\mathrm{B}} \pm 6.194$ & $5.159^{\mathrm{B}} \pm 0.031$ \\
\hline
\end{tabular}

Superscript indices show samples to be significantly different at $\alpha<0.05$ according to Tukey-test

$G S F$ pure grape seed flour, $D W$ dry weight, $G A E$ gallic acid equivalent, number ration of grape product, $S$ grape seed flour, $E$ addition at the end of the production

were added, fat contents were adjusted upstream in order to always get the same fat content in final samples.

Contrary to seed flour the grape pomace must always be dried and pre-ground. It was, therefore, dried in a drying cabinet and also because grinding is easier with lower moisture content. This step was carried out using a ceramic disc mill. The resulting product was either used directly in conventional production (roller refiner and conching) or further ground in a ball mill after mixing with cocoa butter (1:1). This mass was then added into the coarse conching process. In experiments $3.5 \mathrm{P}, 5 \mathrm{P}$ and $7.5 \mathrm{P}$, this was done at the beginning of the process during the conching step. In trials $3.5 \mathrm{P}_{\mathrm{E}}, 5 \mathrm{P}_{\mathrm{E}}, 7.5 \mathrm{P}_{\mathrm{E}}$ and $10 \mathrm{P}_{\mathrm{E}}$, the intermediate product was added to the finished product.

A general focus of all experiments was to produce groups of samples, which do not differ more than $3 \mu \mathrm{m}$ in their maximal particle size X90, which means that 90 volume- $\%$ of particles are smaller than the given value. Flow properties of samples showing uneven particle size cannot be compared, as particle size and the resulting specific surface have a large influence on flow properties [14, 15]. Practically the grinding process was always stopped when reaching the target size.

\section{Recipes and materials}

All milk chocolates were produced using the same recipe, consisting of $15.00 \%$ cocoa liquor, $27.19 \%$ sugar, $17.00 \%$ cocoa butter, $8.00 \%$ lactose, $7.50 \%$ skim milk powder, $4.40 \%$ anhydrous milk fat and $20.91 \%$ added other foodstuffs, thereof $0.70 \%$ lecithin, varying amounts of grape pomace products according to DOE and the remaining part of permeate powder. It contains $30.8 \%$ fat and meets the legal standard of "milk chocolate" according to article 3(5) in European Cocoa Directive 2000/36/EC [6].

All recipes contain $20.91 \%$ added foodstuff. The permeate powder was used to balance the varying contents of grape products (3.5-10\%). It consists mainly of lactose and minerals and was used due to its relatively little influence on chocolate properties and thus behaves like a "neutral filler" [16].

The following raw materials were used: cocoa liquor (Cargill Cocoa SARL; Abidjan, Ivory Coast), cocoa butter (Olam Cocoa Deutschland GmbH, Mannheim, Germany), skim milk powder (DMK Deutsches Milchkontor GmbH, Bremen, Germany), lactose (Wheyco GmbH, Altentreptow, 
Table 4 Mean values and standard deviation for specific surface, span, specific width, particle size of chocolates with grape pomace processed by conventional production or coarse conching with different times of addition

\begin{tabular}{lrrrrrrr}
\hline Trial & $\begin{array}{l}\text { Specific surface } \\
\left(\mathrm{m}^{2} / \mathrm{g}\right)\end{array}$ & \multicolumn{1}{l}{ Span } & \multicolumn{1}{l}{ Specific width } & \multicolumn{1}{l}{$\mathrm{X} 10(\mu \mathrm{m})$} & \multicolumn{1}{l}{$\mathrm{X} 50(\mu \mathrm{m})$} & $\mathrm{X} 90(\mu \mathrm{m})$ & $\mathrm{X} 99(\mu \mathrm{m})$ \\
\hline $\mathrm{OP}$ & $0.914^{\mathrm{D}} \pm 0.031$ & $2.636^{\mathrm{CDE}} \pm 0.047$ & $9.292^{\mathrm{BCDE}} \pm 0.329$ & $3.035^{\mathrm{AB}} \pm 0.123$ & $9.532^{\mathrm{C}} \pm 0.186$ & $28.155^{\mathrm{C}} \pm 0.164$ & $42.683^{\mathrm{CD}} \pm 2.427$ \\
$3.5 \mathrm{P}_{\mathrm{E}}$ & $0.911^{\mathrm{D}} \pm 0.007$ & $2.533^{\mathrm{F}} \pm 0.012$ & $8.704^{\mathrm{E}} \pm 0.059$ & $3.083^{\mathrm{AB}} \pm 0.021$ & $9.376^{\mathrm{CD}} \pm 0.090$ & $26.838^{\mathrm{DE}} \pm 0.360$ & $44.605^{\mathrm{BC}} \pm 0.611$ \\
$5 \mathrm{P}_{\mathrm{E}}$ & $0.956^{\mathrm{BC}} \pm 0.029$ & $2.638^{\mathrm{CDE}} \pm 0.069$ & $8.914^{\mathrm{DE}} \pm 0.364$ & $2.951^{\mathrm{AB}} \pm 0.111$ & $8.844^{\mathrm{E}} \pm 0.257$ & $26.269^{\mathrm{EF}} \pm 0.299$ & $42.762^{\mathrm{CD}} \pm 2.030$ \\
$7.5 \mathrm{P}_{\mathrm{E}}$ & $0.920^{\mathrm{CD}} \pm 0.002$ & $2.551^{\mathrm{EF}} \pm 0.009$ & $8.736^{\mathrm{E}} \pm 0.035$ & $3.056^{\mathrm{AB}} \pm 0.008$ & $9.269^{\mathrm{D}} \pm 0.024$ & $26.700^{\mathrm{DE}} \pm 0.092$ & $43.955^{\mathrm{BCD}} \pm 0.606$ \\
$10 \mathrm{P}_{\mathrm{E}}$ & $0.892^{\mathrm{D}} \pm 0.001$ & $2.718^{\mathrm{BC}} \pm 0.017$ & $10.140^{\mathrm{A}} \pm 0.048$ & $3.039^{\mathrm{AB}} \pm 0.005$ & $10.223^{\mathrm{A}} \pm 0.023$ & $30.819^{\mathrm{A}} \pm 0.134$ & $52.370^{\mathrm{A}} \pm 0.826$ \\
$3.5 \mathrm{P}$ & $0.889^{\mathrm{D}} \pm 0.021$ & $2.672^{\mathrm{BC}} \pm 0.072$ & $9.473^{\mathrm{BCD}} \pm 0.578$ & $3.116^{\mathrm{A}} \pm 0.125$ & $9.852^{\mathrm{B}} \pm 0.036$ & $29.444^{\mathrm{B}} \pm 0.627$ & $50.373^{\mathrm{A}} \pm 0.487$ \\
$5 \mathrm{P}$ & $0.919^{\mathrm{D}} \pm 0.006$ & $2.615^{\mathrm{DEF}} \pm 0.013$ & $8.777^{\mathrm{E}} \pm 0.030$ & $3.080^{\mathrm{AB}} \pm 0.021$ & $9.163^{\mathrm{D}} \pm 0.050$ & $27.038^{\mathrm{D}} \pm 0.261$ & $45.588^{\mathrm{B}} \pm 1.046$ \\
$7.5 \mathrm{P}$ & $0.963^{\mathrm{B}} \pm 0.033$ & $2.641^{\mathrm{BCDE}} \pm 0.090$ & $9.043^{\mathrm{CDE}} \pm 0.541$ & $2.919^{\mathrm{B}} \pm 0.142$ & $8.864^{\mathrm{E}} \pm 0.142$ & $26.320^{\mathrm{E}} \pm 0.304$ & $41.598^{\mathrm{D}} \pm 1.494$ \\
$\mathrm{C} 5 \mathrm{P}$ & $1.067^{\mathrm{B}} \pm 0.005$ & $3.126^{\mathrm{A}} \pm 0.015$ & $9.563^{\mathrm{ABC}} \pm 0.029$ & $2.686^{\mathrm{C}} \pm 0.006$ & $7.357^{\mathrm{G}} \pm 0.017$ & $25.687^{\mathrm{F}} \pm 0.100$ & $42.020^{\mathrm{D}} \pm 0.335$ \\
$\mathrm{C} 0 \mathrm{P}$ & $1.085^{\mathrm{A}} \pm 0.005$ & $2.736^{\mathrm{B}} \pm 0.006$ & $9.732^{\mathrm{AB}} \pm 0.050$ & $2.515^{\mathrm{D}} \pm 0.014$ & $8.027^{\mathrm{F}} \pm 0.014$ & $24.479^{\mathrm{G}} \pm 0.023$ & $34.995^{\mathrm{E}} \pm 0.050$ \\
\hline
\end{tabular}

Superscript indices show samples to be significantly different at $\alpha<0.05$ according to Tukey-test

$C$ conventional production, number ration of grape product, $P$ grape pomace, $E$ addition at the end of the production

Table 5 Mean values and standard deviation for flow property descriptors of chocolates with grape pomace processed by conventional production or coarse conching with different times of addition

\begin{tabular}{|c|c|c|c|c|c|c|}
\hline Trial & $\begin{array}{l}\text { Casson yield value } \\
(\mathrm{Pa})\end{array}$ & $\begin{array}{l}\text { Casson viscosity } \\
(\mathrm{Pa} \mathrm{s})\end{array}$ & $\begin{array}{l}\text { Shear stress at } \\
0.05 \mathrm{~s}^{-1}(\mathrm{~Pa})\end{array}$ & $\begin{array}{l}\text { Shear stress at } 5 \mathrm{~s}^{-1} \\
(\mathrm{~Pa})\end{array}$ & $\begin{array}{l}\text { Shear stress at } 40 \mathrm{~s}^{-1} \\
(\mathrm{~Pa})\end{array}$ & $\begin{array}{l}\text { Viscosity at } 40 \mathrm{~s}^{-1} \\
\text { (Pa s) }\end{array}$ \\
\hline OP & $11.814^{\mathrm{DE}} \pm 0.415$ & $3.410^{\mathrm{AB}} \pm 0.122$ & $9.862^{\mathrm{E}} \pm 0.502$ & $66.170^{\mathrm{D}} \pm 1.165$ & $222.133^{\mathrm{D}} \pm 4.217$ & $5.551^{\mathrm{D}} \pm 0.106$ \\
\hline $3.5 \mathrm{P}_{\mathrm{E}}$ & $10.987^{\mathrm{E}} \pm 0.056$ & $2.061^{\mathrm{E}} \pm 0.080$ & $10.740^{\mathrm{D}} \pm 0.236$ & $44.960^{\mathrm{H}} \pm 1.136$ & $152.567^{\mathrm{I}} \pm 4.455$ & $3.815^{\mathrm{I}} \pm 0.111$ \\
\hline $5 \mathrm{P}_{\mathrm{E}}$ & $12.265^{\mathrm{CD}} \pm 0.204$ & $2.203^{\mathrm{E}} \pm 0.026$ & $10.953^{\mathrm{C}} \pm 0.396$ & $50.657^{\mathrm{G}} \pm 0.260$ & $164.033^{\mathrm{H}} \pm 0.795$ & $4.099^{\mathrm{H}} \pm 0.015$ \\
\hline $7.5 \mathrm{P}_{\mathrm{E}}$ & $14.055^{\mathrm{B}} \pm 0.220$ & $2.961^{\mathrm{C}} \pm 0.040$ & $12.237^{\mathrm{B}} \pm 0.384$ & $64.653^{\mathrm{E}} \pm 0.245$ & $210.367^{\mathrm{E}} \pm 1.080$ & $5.261^{\mathrm{E}} \pm 0.025$ \\
\hline $10 \mathrm{P}_{\mathrm{E}}$ & $15.307^{\mathrm{A}} \pm 0.357$ & $3.667^{\mathrm{A}} \pm 0.023$ & $12.720^{\mathrm{A}} \pm 0.393$ & $77.527^{\mathrm{A}} \pm 0.314$ & $250.633^{\mathrm{A}} \pm 1.449$ & $6.265^{\mathrm{A}} \pm 0.035$ \\
\hline $3.5 \mathrm{P}$ & $13.161^{\mathrm{BC}} \pm 0.444$ & $3.386^{\mathrm{B}} \pm 0.044$ & $11.353^{\mathrm{D}} \pm 0.490$ & $67.590^{\mathrm{B}} \pm 0.786$ & $228.067^{\mathrm{B}} \pm 3.054$ & $5.701^{B} \pm 0.073$ \\
\hline $5 \mathrm{P}$ & $13.208^{\mathrm{BC}} \pm 0.122$ & $3.389^{\mathrm{B}} \pm 0.018$ & $11.483^{\mathrm{C}} \pm 0.200$ & $66.930^{\mathrm{BC}} \pm 0.535$ & $227.60^{\mathrm{BC}} \pm 0.879$ & $5.690^{\mathrm{BC}} \pm 0.019$ \\
\hline 7.5P & $13.410^{\mathrm{B}} \pm 0.177$ & $3.295^{\mathrm{B}} \pm 0.109$ & $11.930^{\mathrm{B}} \pm 0.328$ & $66.277^{\mathrm{CD}} \pm 1.539$ & $225.067^{\mathrm{C}} \pm 5.329$ & $5.626^{\mathrm{C}} \pm 0.136$ \\
\hline C5P & $15.356^{\mathrm{A}} \pm 0.336$ & $2.604^{\mathrm{D}} \pm 0.065$ & $12.650^{\mathrm{A}} \pm 0.560$ & $64.647^{\mathrm{E}} \pm 0.621$ & $195.733^{\mathrm{F}} \pm 2.279$ & $4.893^{\mathrm{F}} \pm 0.057$ \\
\hline $\mathrm{COP}$ & $9.752^{\mathrm{F}} \pm 0.238$ & $2.867^{\mathrm{CD}} \pm 0.144$ & $7.664^{\mathrm{F}} \pm 0.236$ & $57.643^{\mathrm{F}} \pm 1.184$ & $184.967^{\mathrm{G}} \pm 4.254$ & $4.626^{\mathrm{G}} \pm 0.107$ \\
\hline
\end{tabular}

Superscript indices show samples to be significantly different at $\alpha<0.05$ according to Tukey-test

$C$ conventional production, number ration of grape product, $P$ grape pomace, $E$ addition at the end of the production

Germany), permeate powder (Wheyco GmbH, Altentreptow, Germany), vanillin (Silesia Gerhard Hanke GmbH and Co. KG, Neuss, Germany) lecithin (Cargill Texturizing Solutions Deutschland GmbH and Co. KG, Hamburg, Germany), crystal sugar (Nordzucker AG, Braunschweig, Germany), anhydrous milk fat (Uelzena eG, Uelzen, Germany), grape pomace (Senger Naturrohstoffe, Dransfeld, Germany) and grape seed flour (Lipoid GmbH, Ludwigshafen, Germany).

\section{Production of samples by coarse conching}

For initial mixing, coarse conching and liquefaction, a pilotscale conch with an integrated vortex chamber (IMR-E 300, Lipp Mischtechnik GmbH, Mannheim, Germany) was used. Skim milk powder, lactose, permeate powder, sugar and grape pomace (if used) were treated in the conch at $37 \mathrm{~Hz}$ with the vortex chamber running at $60 \mathrm{~Hz} .3 \%$ added fat reduced dusting but did not hinder evaporation. After achieving a moisture content below $1 \%$, the cocoa mass and a portion of cocoa butter were added to achieve a fat content of $12-15 \%$, coarse conching continues for $90 \mathrm{~min}$, reaching a product temperature of $70-75{ }^{\circ} \mathrm{C}$, which is adequate for reducing the water content to $<0.6 \%$. In the last step the missing ingredients were added apart from lecithin. For the unloading of the conch the product temperature was reduced to $50{ }^{\circ} \mathrm{C}$.

The grinding process was performed in a ball mill IMPACTOR ${ }^{\circledR}$ IMP5 (Lipp, Mannheim, Germany) with $15 \mathrm{~kg}$ of hardened steel balls of either $6.35 \mathrm{~mm}$ diameter with the frequency converter set to $25 \mathrm{~Hz}$. Power consumption of the 
Table 6 Mean values and standard deviation for total phenol content and antioxidative capacity of chocolates with grape pomace processed by conventional production or coarse conching

\begin{tabular}{lcc}
\hline Trial & mg GAE/100 g DW & mmol Trolox/100 g DW \\
\hline GP & $6751.502^{\mathrm{A}} \pm 148.211$ & $60.718^{\mathrm{A}} \pm 4.077$ \\
$0 \mathrm{P}$ & $281.746^{\mathrm{CD}} \pm 11.425$ & $2.425^{\mathrm{B}} \pm 0.161$ \\
$3.5 \mathrm{P}_{\mathrm{E}}$ & $388.458^{\mathrm{BCD}} \pm 36.597$ & $2.872^{\mathrm{B}} \pm 0.040$ \\
$5 \mathrm{P}_{\mathrm{E}}$ & $458.731^{\mathrm{BCD}} \pm 23.184$ & $3.647^{\mathrm{B}} \pm 0.083$ \\
$7.5 \mathrm{P}_{\mathrm{E}}$ & $555.211^{\mathrm{B}} \pm 4.093$ & $4.227^{\mathrm{B}} \pm 0.212$ \\
$10 \mathrm{P}_{\mathrm{E}}$ & $631.597^{\mathrm{B}} \pm 8.267$ & $4.854^{\mathrm{B}} \pm 0.241$ \\
$3.5 \mathrm{P}$ & $396.801^{\mathrm{BCD}} \pm 20.478$ & $3.115^{\mathrm{B}} \pm 0.169$ \\
$5 \mathrm{P}$ & $433.586^{\mathrm{BCD}} \pm 10.528$ & $3.425^{\mathrm{B}} \pm 0.144$ \\
$7.5 \mathrm{P}$ & $521.316^{\mathrm{BC}} \pm 11.779$ & $4.263^{\mathrm{B}} \pm 0.023$ \\
C5P & $375.170^{\mathrm{BCD}} \pm 23.184$ & $3.022^{\mathrm{B}} \pm 0.179$ \\
C0P & $204.598^{\mathrm{D}} \pm 3.259$ & $1.718^{\mathrm{B}} \pm 0.011$ \\
\hline
\end{tabular}

Superscript indices show samples to be significantly different at $\alpha<0.05$ according to Tukey-test

$D W$ dry weight, $G A E$ gallic acid equivalent, $C$ conventional production, number ration of grape product, $P$ grape pomace, $E$ addition at the end of the production

mill was kept at $2.5 \pm 0.2 \mathrm{~kW}$ by frequently adding lecithin and thus controlling mass consistency. The double-jacket was tempered using a thermostat (Regloplas, St. Gallen, Switzerland); at the beginning it was set to $50{ }^{\circ} \mathrm{C}$ for keeping the fat liquid. Later during milling the temperature was reduced to keep the mass under $60{ }^{\circ} \mathrm{C}$, which should prevent glass transition of lactose [17]. The mass was circulated through the ball mill by an eccentric screw pump (MDT 0256L, Seepex, Bottrop, Germany). Particle size was controlled by a micrometre calliper (Vogel, Kevalear, Germany).

\section{Production of samples by conventional processing}

For the chocolates that were produced with the conventional method a 3-roll-refiner (WDLH 300, F.B. Lehmann GmbH, Aalen, Germany) was used. The details of the standardized settings were shown in [14]. Then liquefaction of the mass took place in the pilot-scale conch, fat and lecithin were added according to the recipe. The overall conching time was $90 \mathrm{~min}$, reaching a final product temperature of $80^{\circ} \mathrm{C}$, which is adequate for achieving $<0.5 \%$ water. This standard small-scale process provides good flow and sensory properties and is detailed in [18].

\section{Drying, pre-grinding, fine grinding and blending with grape products}

The supplied dry grape pomace with a residual moisture of 7-9\% was further dried at $60{ }^{\circ} \mathrm{C}$ in a drying cabinet (Haraeus Holding $\mathrm{GmbH}$, Hanau, Germany) until the product achieved a moisture content of $4-5 \%$. Pre-grinding of the dried material was performed using a ceramic disc mill (Super Masscolloider MK CA6-3, Masuko Sangyo Co. Ltd, Kawaguchi, Japan) at $10 \mathrm{~Hz}$ applying five passages while decreasing gap widths.

The material was then mixed with cocoa butter $(1: 1)$ and the fine-grinding was performed using the ball mill with $15 \mathrm{~kg}$ of hardened steel balls of $6.35 \mathrm{~mm}$ diameter and with the frequency converter set to $25 \mathrm{~Hz}$; the target size is $\mathrm{X} 90<30 \mu \mathrm{m}$. The double-jacket was tempered at $50{ }^{\circ} \mathrm{C}$ for keeping the fat liquid, but the mass temperature should not exceed $60{ }^{\circ} \mathrm{C}$.

The final grinding step with the ball mill was likewise applied on grape seed flour but without pre-grinding or drying.

The produced intermediate masses were used in the conching step or mixed into the finished chocolate according to the experimental design.

\section{Production of samples by tempering and using of crystallization nuclei}

The masses were tempered by a tempering machine (Sollich, Bad Salzuflen, Germany) or by using crystallization nuclei (Mycryo ${ }^{\circledR}$, Barry Callebaut AG, Lebbeke-Wieze, Belgium). In the latter case less fat was added upstream in order to keep final fat content constant. Tablets were made using neutrally, identically shaped $100 \mathrm{~g}$ plastic moulds. These were put immediately on a vibrating table (Nettler, Mainz, Germany) for even distribution and removal of air bubbles. After solidification in a cooling cell they were unmoulded, acclimatised at room temperature, packed in aluminium foil and allowed to rest at $15{ }^{\circ} \mathrm{C}$ for final crystallisation.

\section{Particle size distribution}

This was measured by laser diffractometer Mastersizer 2000 (Malvern Instruments, Worcestershire, UK) according to Fraunhofer theory [19], which is most appropriate for mixtures of particles showing different optical properties. The samples were diluted 1:100 with sunflower oil at $40^{\circ} \mathrm{C}$ and treated for $15 \mathrm{~min}$ in an ultrasonic bath (Sonorex Bandelin, Berlin, Germany). The preparation was added to the instrument, while oil was circulating. The sample preparation was done twice and the measurement carried out threefold, resulting in six data sets per sample.

The mean results of PSD quantiles X99, X90, X50, X10 are given including standard deviation. The values of specific surfaces are calculated by the instrument software from the PSD assuming particles are spherical. Specific width $\mathrm{X} 90 / \mathrm{X} 10$ is a parameter that can make a statement about the width of the PSD; span $(\mathrm{X} 90-\mathrm{X} 10) / \mathrm{X} 50$ is used for the same purpose. 
X99 is not commonly used for chocolate. The pomace and especially the seeds are harder and more difficult to mill than all other raw materials. When they are not fine enough, the small amounts according to recipes are not detected by the X90. Therefore, the X99 represents mainly the pomace particles and determines the maximum size of all particles. Otherwise, one could find acceptable values for X90 and then be surprised by finding sandy mouthfeel in sensory evaluation.

For all data ANOVA identified differences between sample means within comparable sample groups, followed by Tukey-test to proof significance of differences between pairs.

\section{Flow properties}

Those were measured in triplicate on a shear rate controlled rotary rheometer (Physica, Stuttgart, Germany), applying cylinder gap system Z3 according to ISO 3219. Compared to the original method-measuring from 60 to $5 \mathrm{~s}^{-1}$ - the range of shear rate was extended below $5 \mathrm{~s}^{-1}$ to improve yield value results. Likewise, shear stress $(\tau)$ at three different shear rates $\left(0.05,5\right.$ and $\left.40 \mathrm{~s}^{-1}\right)$ was recorded as recommended by the International Confectionery Association (ICA, formerly IOCCC) [20, 21]. $\tau_{40}$ was also used to calculate apparent viscosity $\eta_{40}$.

Additionally, data from the flow curves were prepared by the Casson method. It uses the given shear rate $(D)$ and the measured shear stress $(\tau)$ to calculate Casson viscosity $\left(\eta_{\mathrm{CA}}\right)$ and Casson yield value $\left(\tau_{\mathrm{CA}}\right)$. The method is no longer recommended due to deviations in a laboratory ring test [20], but is still widely used in the industry and allows comparing results to existing data as recommended in [21].

\section{Total phenol content}

The total phenol content was measured using the Folin-Ciocalteu method. It is based on the electron transfer in the alkaline medium by reducing of substances. Molybdenum forms blue complexes being detected by a photometer at $725 \mathrm{~nm}[22]$.

For producing an extract the chocolate sample must be defatted with $\mathrm{n}$-hexane in the first place. Phenol extraction was then performed by an extraction medium consisting of $80 \%$ methanol, $19 \%$ distilled water and $1 \%$ acetic acid according to $[23,24]$. The extract $(100 \mu \mathrm{l})$ was added to $750 \mu \mathrm{l}$ of $10 \%$ Folin-Ciocalteu reagent and then incubated for $5 \mathrm{~min}$. Afterwards the mixture was mixed well with $750 \mu \mathrm{Na}_{2} \mathrm{CO}_{3}$ solution $(60 \mathrm{~g} / \mathrm{l})$ and maintained for $90 \mathrm{~min}$ in a dark place. The absorbance was measured at $725 \mathrm{~nm}$ in a spectrophotometer (UV-3100PC spectrophotometer, VWR International GmbH, Darmstadt, Germany). The calculation of the results is based on extraction volume, original sample weight and the measured value of the photometer. The result is stated as PP (polyphenol) $\mathrm{mg} / 100 \mathrm{~g} \mathrm{DW}$ (dried weight) based on the calibration curve.

\section{Antioxidative capacity}

The "ferric-reducing antioxidant power" (FRAP) assay measures the strength of antioxidants at a low $\mathrm{pH}$ value by reducing the ferric-tripyridyltriazine complex $\left(\mathrm{Fe}^{3+}-\mathrm{TPTZ}\right)$ into ferrous complex ( $\mathrm{Fe}^{2+}$-TPTZ) [25]. The same extract as for total phenol content was used, so $40 \mu \mathrm{l}$ was added to $1800 \mu \mathrm{l}$ FRAP reagent and then filled up with $60 \mu \mathrm{l}$ distilled water. The FRAP reagent consists of TPTZ solution $(10 \mathrm{mM}$ in $40 \mathrm{mM} \mathrm{HCl})$, acetate buffer $(\mathrm{pH} \mathrm{3.6})$ and $\mathrm{FeCl}_{3} 6 \mathrm{H}_{2} \mathrm{O}$ $(20 \mathrm{mM})$. The cuvettes are stored in the dark for $180 \mathrm{~min}$ and then measured at $593 \mathrm{~nm}$. The calculation of the results is based on extraction volume, original sample weight and the measured value of the photometer. The result is stated as mmol trolox/100 g DW (dried weight) based on the calibration curve.

\section{Sensory evaluation}

For sensory analysis of selected chocolate samples the simple descriptive test (DIN 10964) was performed by six panellists already familiar with sensory methods. The evaluation was carried out in standardised individual cabins [26]. In each session all samples were presented with three-digit randomized numbers. The panellists described only the individual attributes, but not their intensity. The categories to be rated was appearance, smell, taste and texture/consistency [27]. For the evaluation a group report was created from the individual reports and the attributes sorted according to frequency.

In addition a hedonic acceptance test was conducted by 21 panellists. They rated the samples in four categories on a nine point scale. For the evaluation of the hedonic acceptance the mean values that were calculated in each category. Also the individual values were classified into three categories as liking (9-7), neutral (6-4) and disliking area (3-1).

For all data ANOVA at $\alpha<0.05$ identified differences between sample means within comparable sample groups, followed by Tukey-test to proof significance of differences between pairs.

\section{Results}

\section{Drying, grinding properties and polyphenol contents of pomace products}

In pre-trials not detailed here different drying methods were used like fluidized bed dryer, freeze dryer and drying cabinet $[28,29]$. Those showed that fluidized bed dryer and drying 
cabinet were gentle options for the polyphenols; the latter was easier to handle and was then further used. At the beginning fresh grape pomace was dried and separated in skins and seeds. It was shown in [30] that material obtained predried needs further drying before use. The drying cabinet at $60{ }^{\circ} \mathrm{C}$ had to be used for $4-6.5 \mathrm{~h}$ in order to achieve final moisture contents of $4-5 \%$. In an industrial process other options could be used to achieve low moisture contents gently, e.g., belt or drum dryers.

In other pre-trials $[29,30]$ raw pomace (size up to $1 \mathrm{~mm}$ ) was put into the first stage of the coarse conching process. It was observed that contrary to sugar there is no grinding of grape pomace by the vortex chamber. Downstream the pomace particles blocked the gaps of the ball mill, which keep the steel balls in the grinding chamber. It was concluded that due to the texture of the material a pre-grinding step is essential. This was feasible by pin-mill or ceramic disk mill, although difficult. Apart from being hard and tenacious the material separates and sticks to the mill [29]. Nevertheless, it was possible by dry-grinding to reduce particle size to 200-300 $\mu \mathrm{m}$. The experiments with the ceramic disk mill showed that an effective drying process is essential for an optimal pre-grinding.

For initial analysis of polyphenol contents aceton had been used for extraction instead of methanol. This makes numerical values incomparable to those presented later, so results are not shown here. Compared to each other they showed that grape seeds contain almost as much polyphenols as cocoa liquor. Values of the latter should be roughly doubled, if the fat content is eliminated and only fat free particles are considered. So cocoa remains the preferable source of polyphenols, although grape seeds can be a good substitute. A freeze-dried sample showed the highest content, so quality depends on gentle drying [28-30].

Red wine is usually pressed from fermented grapes, so polyphenols will be extracted from peels into wine. Thus theoretically more polyphenols can be expected in unfermented pomace from juice production. A few pomace samples of fermented and unfermented pomace from varying cultivars were analysed for polyphenols and FRAP [31]. Results indicated higher contents in unfermented pomace, but the number of samples was too small and heterogeneous for further conclusions.

\section{Chocolates containing grape seed flour}

\section{Pre-trials}

In one of the first pre-trials the use of self-ground grape seeds was compared with grape seed flour. No suitable particle sizes could be achieved with grape seeds [28]. Therefore, grape seed flour was used in the following experiments as a chocolate ingredient [32]. It is a good option because the material is already ground and no further drying and grinding steps were necessary before the final grinding in the ball mill took place. Grape seed flour could be grinded faster in the ball mill than the fibrous grape pomace [31,32].

\section{Particle size distribution}

Table 1 shows that the products have a similar X90 of $23 \pm 2 \mu \mathrm{m}$, which makes the products comparable. The X99 is low with values just above $30 \mu \mathrm{m}$ and thus no grape seed particles had slipped through the mill. This shows that it is possible to reach ideal particle sizes without pre-drying and grinding.

For trials in Fig. 1 untreated grape seed flour was added before the process had started. Figure 2 shows those trials, where grape seed flour was used, which had been pre-ground in the ball mill together with cocoa butter. The intermediate product was added at the beginning or at the end of the process. The graphs look very similar. Only the standard and $5 S^{\mathrm{I}}$ have a slightly lower proportion of small particles. Some samples—-most expressed at $5 \mathrm{~S}_{\mathrm{E}}^{\mathrm{II}}$ - show a slight trend to a bimodal distribution, which is generally considered as positive $[14,15,33]$.

\section{Flow properties}

Those are shown in Table 2 and illustrated by some selected flow curves in Fig. 3. All values and curves are relatively close to each other. Nevertheless, there is some inconsistency within the trials using $5 \%$ seed flour; sample $5 \mathrm{~S}^{\mathrm{I}}$ with pre-ground flour added in the beginning shows the lowest values. The other two with addition at the end are higher and also different from each other. Hypothetically, in this case the grape seed particles could have been not well covered with fat or even agglomerated due to the low shear manual mixing of chocolate and intermediate product. Sample 10S shows slightly lower shear stress at high shear rates. This single result seems too weak to speculate about a trend. Looking at the entire sample set, the most probable overall conclusion is that amount of grape seed flour, pre-treatment and time of addition have no or just little impact on flow properties.

\section{Total phenol content and antioxidative capacity}

The first line in Table 3 shows that pure grape seed flour contains a high amount of polyphenols. Chocolate samples are ordered by increasing addition. The first column shows a trend that incorporation can increase the total phenol content of the resulting chocolate. The second column shows that also the Antioxidative capacity increases as in the first column. The repetitions of the trials with the same grape portions sometimes have different values. A reason for this 
Fig. 1 Particle size distribution of milk chocolates produced by coarse conching and enriched with untreated grape seed flour; addition took place at the beginning of production $(\mathrm{S}=$ grape seed flour, number $=$ ration of grape product)
Fig. 2 Particle size distribution of milk chocolates produced by coarse conching and enriched with grape seed flour pregrinded in the ball mill; addition took place at the beginning or at the end of production $(\mathrm{S}=$ grape seed flour, $\mathrm{E}=$ addition at the end, number $=$ ration of grape product)
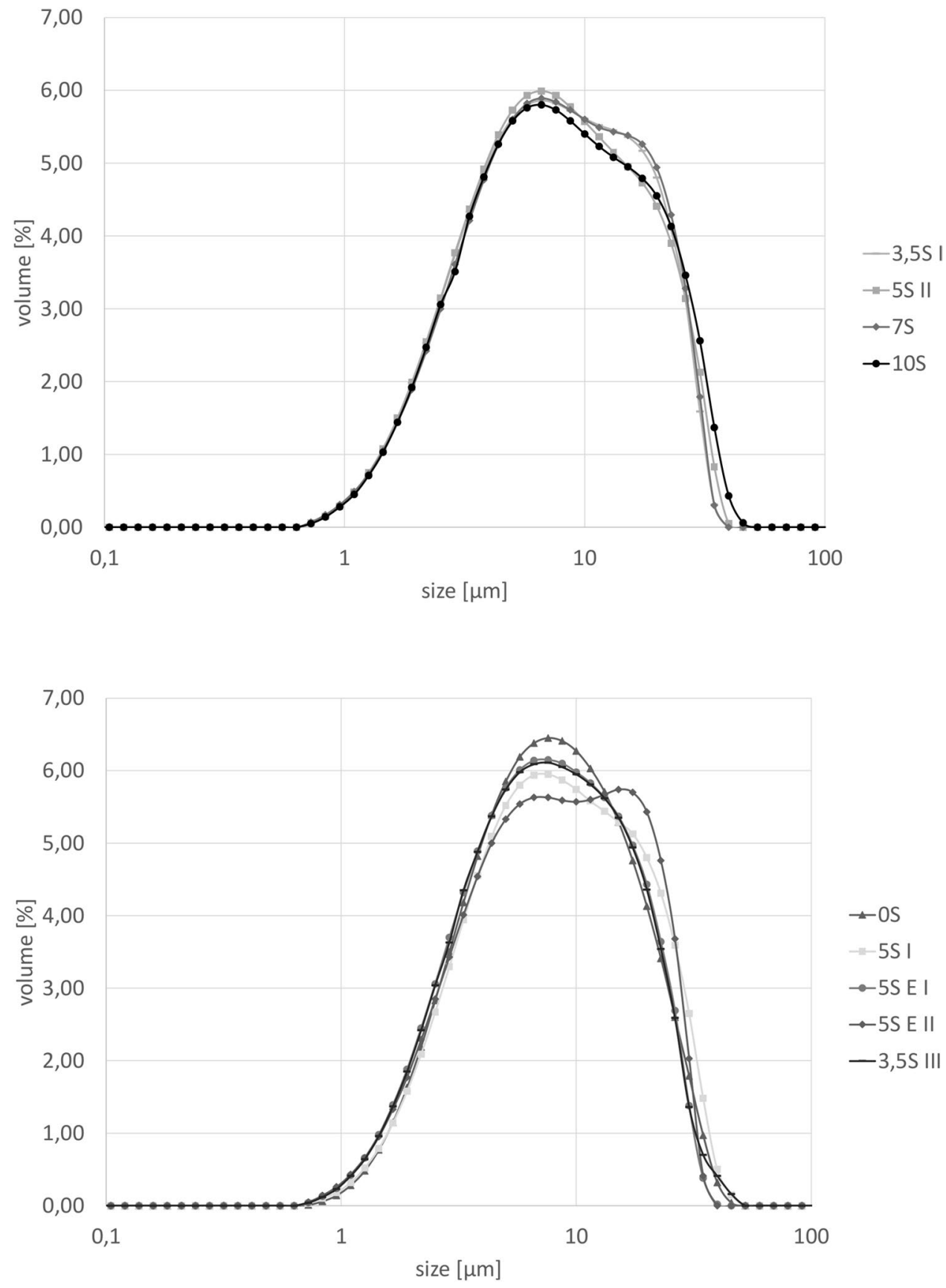

could be the treatment of the raw material, for example pregrinding in the ball mill or duration of processing together with chocolate.

\section{Chocolates containing grape pomace}

\section{Pre-trials}

Various drying and grinding options were performed in order to find the best variant. This has shown that fresh grape pomace was difficult to handle and could not be dried in the conching step [16]. After that, pre-dried pomace was used and its moisture content reduced to the target value. Pin mill, disk mill, roller mill and ball mill were used to find the optimal grinding variant. In any case it was necessary to have at least two grinding steps [30]. The first grinding step was performed with pin mill or disk mill. Smaller particle sizes could be achieved with the disk mill by stepwise reducing the gap width. The second grinding step was performed with the roller mill or the ball mill. However, the use of the ball mill was much more efficient to grind large quantities for a longer time [31]. 
Fig. 3 Flow curves of selected milk chocolates enriched with grape seed flour, produced with coarse conching and addition at the beginning of production (number $=$ ration of grape product, $\mathrm{S}=$ grape seed flour)

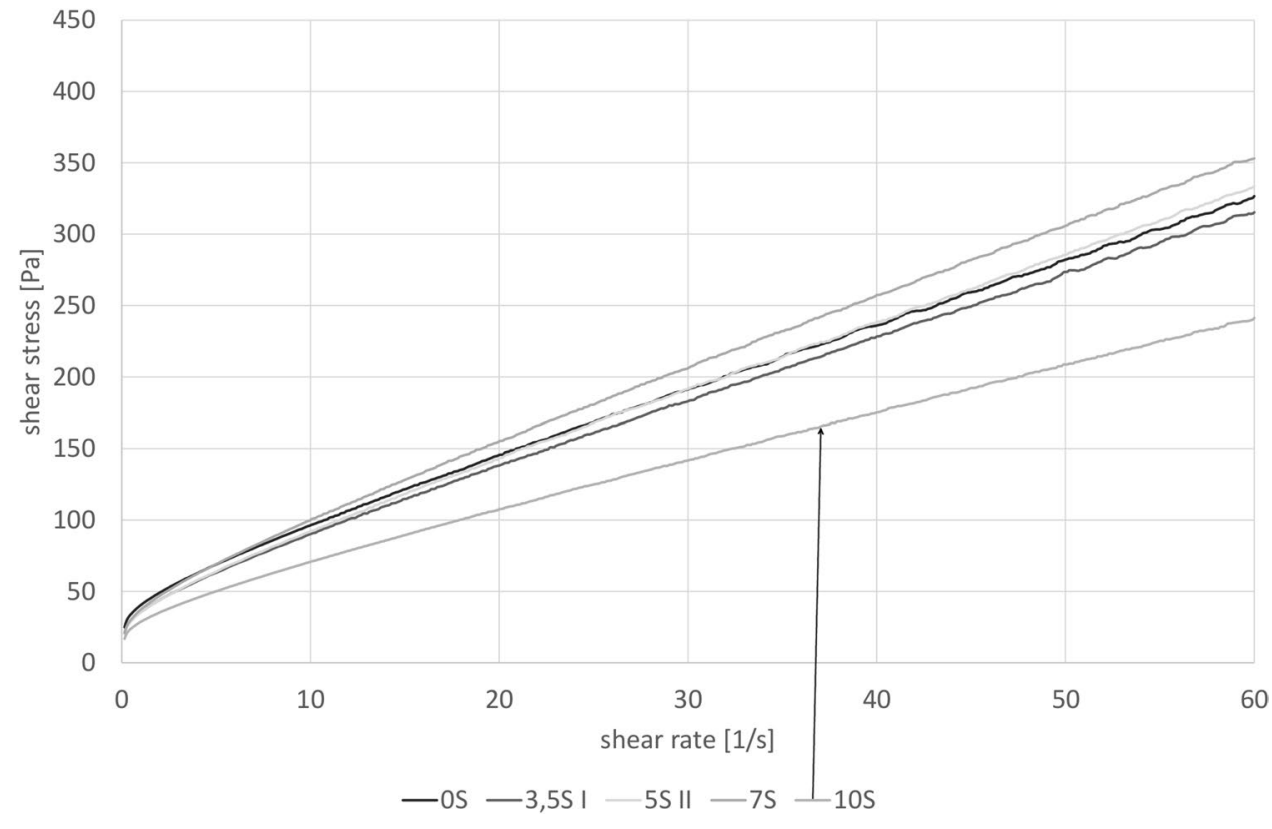

\section{Particle size distribution}

Table 4 shows that the products have a similar X90 of $28 \pm 3 \mu \mathrm{m}$, making the products comparable. Figures. 4, 5 show a very similar particle size distribution, although trials $10 \mathrm{P}_{\mathrm{E}}$ and $3.5 \mathrm{P}$ show a slightly higher portion of bigger particles. X99 values of clearly over $30 \mu \mathrm{m}$ indicate there might be sensory noticeable particles. It was concluded that due to the rapid movement in the ball mill some tenacious particles can slip through without being properly ground.
Specific surface increases with higher amounts of smaller particles; overall, relative width, span and specific surface are similar.

The products with grape pomace being added in the beginning had an overall longer grinding time but still higher X90 values.

Figure 6 shows PSDs of samples made conventionally by a roller refiner. Those are different to the ball mill samples and show a trend towards more bimodal distributions, which was to be expected $[14,15]$.
Fig. 4 Particle size distribution of milk chocolate enriched with grape pomace, produced with coarse conching and addition at the end of the production (number $=$ ration of grape product, $\mathrm{P}=$ grape pomace, $\mathrm{E}=$ addition at the end of the production)

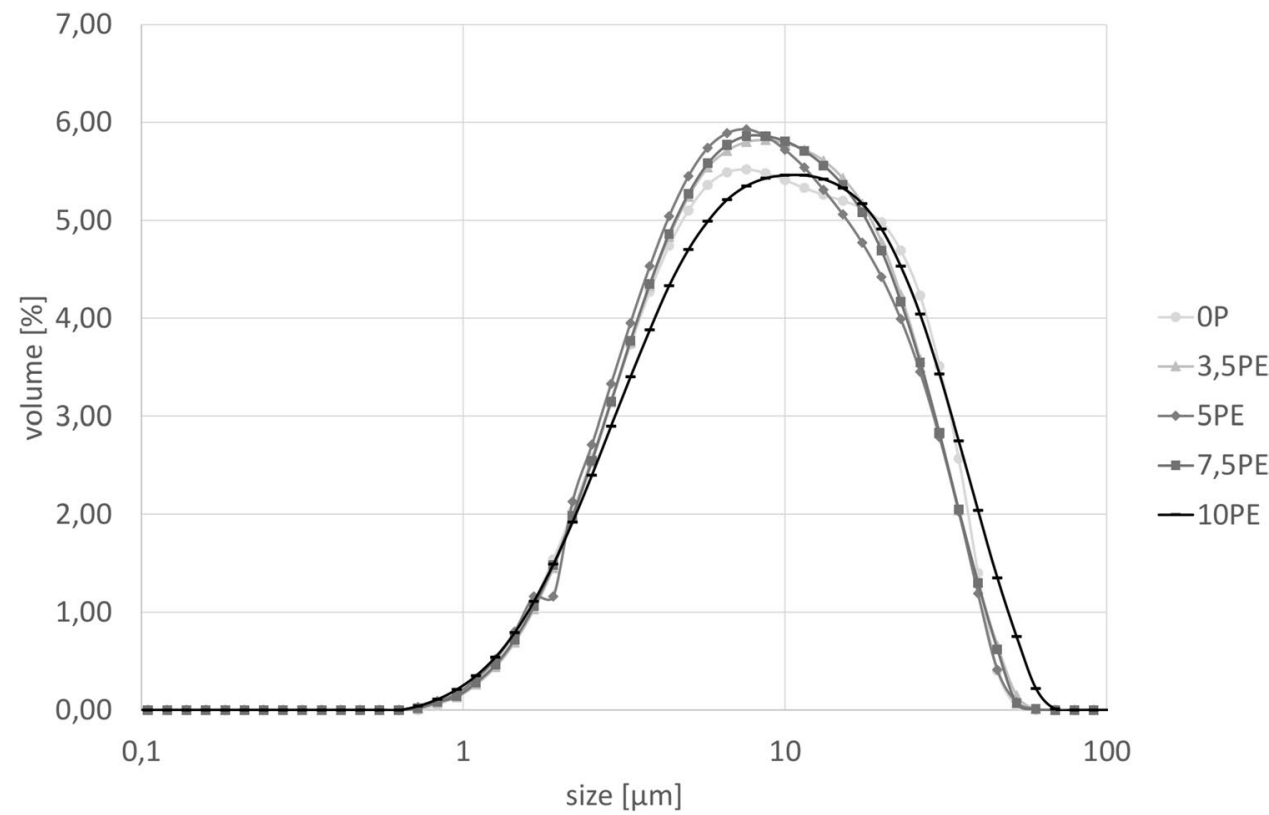


Fig. 5 Particle size distribution of milk chocolate enriched with grape pomace, produced with coarse conching and addition at the beginning of the production (number $=$ ration of grape product, $\mathrm{P}=$ grape pomace)
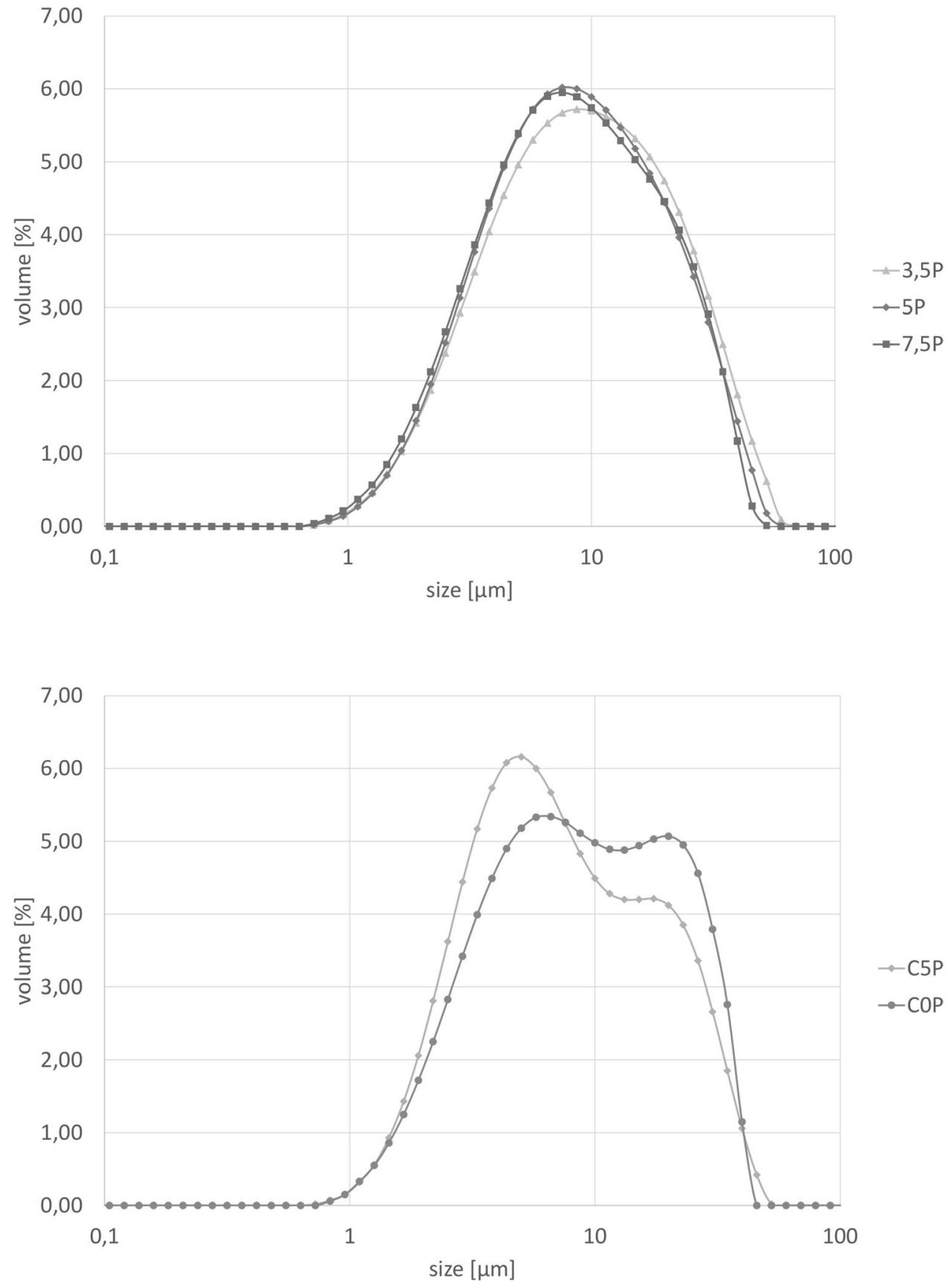

Fig. 6 Particle size distribution of milk chocolate enriched with grape pomace, produced with conventional production $(\mathrm{C}=$ conventional production; number $=$ ration of grape product, $\mathrm{P}=$ grape pomace)

\section{Flow properties}

All results are listed in Table 5. Figure 7 shows flow curves of samples with fine-ground intermediate product added to final mass. Here a slight increase of all values together with increasing amount of pomace can be seen. In contrary the values where pomace was added initially are very close to each other, flow curves (not shown here) look almost identical.

The two conventionally made samples show a larger difference at low shear $\left(\tau_{\mathrm{CA}}, \tau_{0.05}\right)$ but are very close at high shear $\left(\eta_{\mathrm{CA}}, \eta_{40}\right)$. Also these flow curves (not shown here) look very close and just different when zooming in at the lower end.

From the results one could conclude again that pomace has little impact on flow properties when given the chance for intensive contact during the entire process. A hypothesis could be that adding the product just in the end does not provide enough impact to cover particle surfaces properly and thus increases flow parameters. 
Fig. 7 Flow curves of milk chocolate enriched with grape pomace, produced with coarse conching and addition of grape product at the end of the production (number $=$ ration of grape product, $\mathrm{P}=$ grape pomace, $\mathrm{E}=$ addition at the end of the production)

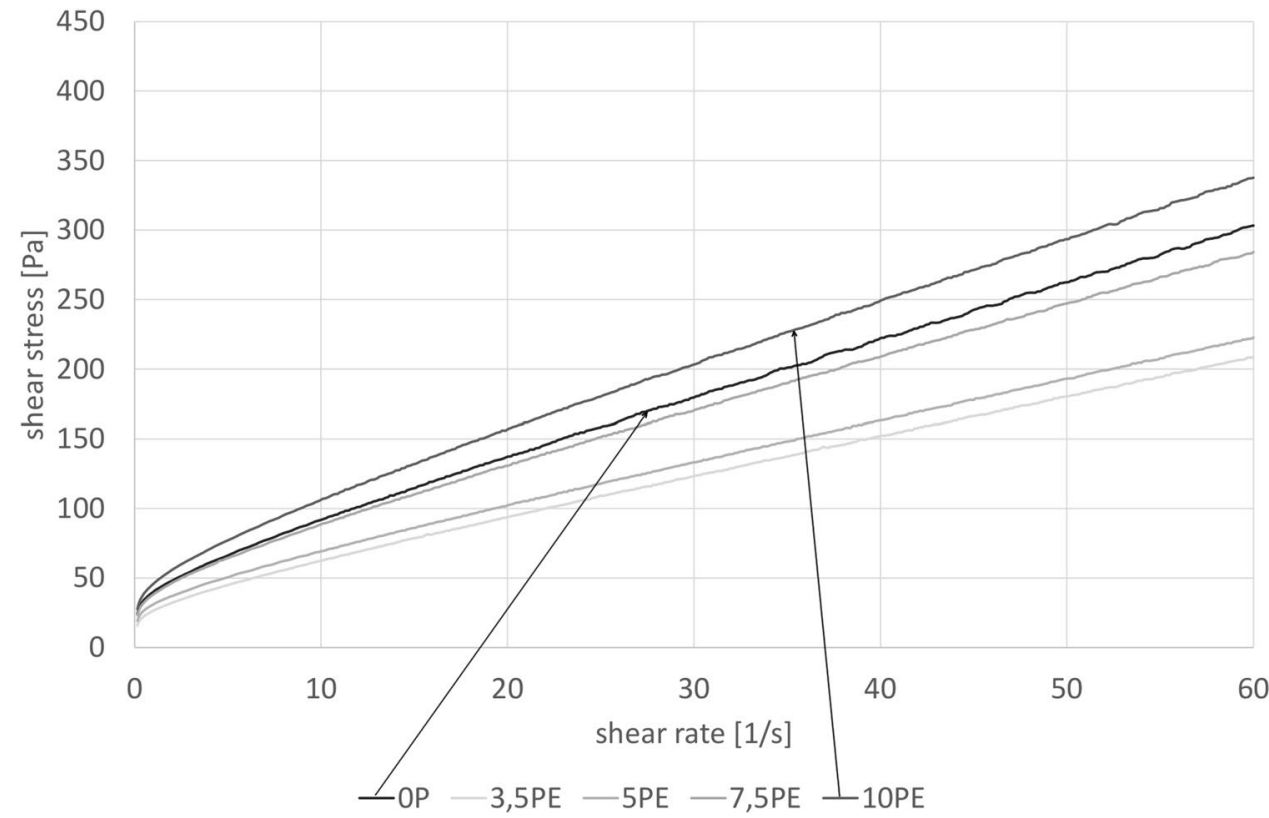

\section{Total phenol content and antioxidative capacity}

First line of Table 6 shows that a high amount of polyphenols can be found in the initial grape pomace; it is also much higher than the one found in grape seed flour (Table 3). Regarding chocolates, there is a positive correlation between grape pomace portion and total phenol content. The same applies for antioxidative capacity from FRAP-test; results from both parameters correlate at $R^{2}=0.977$. Based on content in pomace, a sample containing, e.g., $3.5 \%$ pomace should show about $236 \mathrm{mg} \mathrm{GAE} / 100 \mathrm{~g}$ DW. The values are higher due to polyphenol coming from cocoa particles. Thus adding only small portions increases the total polyphenol content of milk chocolate significantly.

\section{Sensory evaluation}

In the pre-trials it had been shown by simple descriptive test (DIN 10964) that samples containing grape seed flour showed little difference to the standard regarding taste [28, 30]; the actual samples showed the same. Thus a sub-set of six chocolates with grape pomace were selected as the more interesting product; results are shown in Table 7. Regarding overall popularity, most chocolates containing pomace were rated significantly better than the reference product. Within this group the differences were not significant. The fruity taste was noted positively in the simple descriptive test. The darker colour associated with a higher proportion of grape pomace was detected and did not have a negative effect. The sample containing $10 \%$ pomace scored lowest regarding acceptance of texture. Regarding overall liking it was not significantly different from all other samples but
Table 7 Mean values and standard deviation for hedonic acceptance test of chocolates with grape pomace processed by coarse conching

\begin{tabular}{lrllr}
\hline Trial & $\begin{array}{l}\text { Overall popular- } \\
\text { ity }\end{array}$ & Colour & \multicolumn{1}{l}{ Taste } & \multicolumn{1}{l}{ Texture } \\
\hline $0 \mathrm{P}$ & $5.38^{\mathrm{B}} \pm 2.17$ & $7.00^{\mathrm{A}} \pm 1.69$ & $5.00^{\mathrm{B}} \pm 2.25$ & $6.81^{\mathrm{AB}} \pm 1.33$ \\
$5 \mathrm{P}_{\mathrm{E}}$ & $7.29^{\mathrm{A}} \pm 1.28$ & $7.43^{\mathrm{A}} \pm 1.18$ & $7.19^{\mathrm{A}} \pm 1.22$ & $7.43^{\mathrm{A}} \pm 1.09$ \\
$7.5 \mathrm{P}_{\mathrm{E}}$ & $6.81^{\mathrm{A}} \pm 1.30$ & $7.19^{\mathrm{A}} \pm 1.33$ & $6.95^{\mathrm{A}} \pm 1.36$ & $7.14^{\mathrm{AB}} \pm 1.08$ \\
$10 \mathrm{P}_{\mathrm{E}}$ & $6.29^{\mathrm{AB}} \pm 1.28$ & $7.38^{\mathrm{A}} \pm 1.29$ & $6.67^{\mathrm{A}} \pm 1.28$ & $6.24^{\mathrm{B}} \pm 1.44$ \\
$5 \mathrm{P}$ & $7.14^{\mathrm{A}} \pm 1.25$ & $7.43^{\mathrm{A}} \pm 1.18$ & $6.90^{\mathrm{A}} \pm 1.54$ & $7.57^{\mathrm{A}} \pm 1.18$ \\
$7.5 \mathrm{P}$ & $7.48^{\mathrm{A}} \pm 1.10$ & $7.57^{\mathrm{A}} \pm 1.18$ & $7.19^{\mathrm{A}} \pm 1.53$ & $7.67^{\mathrm{A}} \pm 0.89$ \\
\hline
\end{tabular}

Superscript indices show samples to be significantly different at $\alpha<0.05$ according to Tukey-test

$P$ grape pomace, number ration of grape product, $E$ addition at the end of the production

scored second to last, just between the reference and the other samples containing moderate amounts of grape pomace. The high amount of non-melting particles might have been notable for and not appreciated by some panellists.

\section{Discussion}

Figure 8 summarizes the correlation of polyphenol contents found in chocolate after adding either grape seed flour or grape pomace. Adding more material containing polyphenols increases also the contents in final products; similar results were found in $[7,24,34,35]$. The concept was proved to be principally feasible. Although milk chocolates naturally contain some polyphenols coming from cocoa particles, both ingredient types are able to significantly increase 
Fig. 8 Correlation of added amounts of grape products to measured polyphenol contents $(\mathrm{S}=$ seeds, $\mathrm{P}=$ pomace $)$

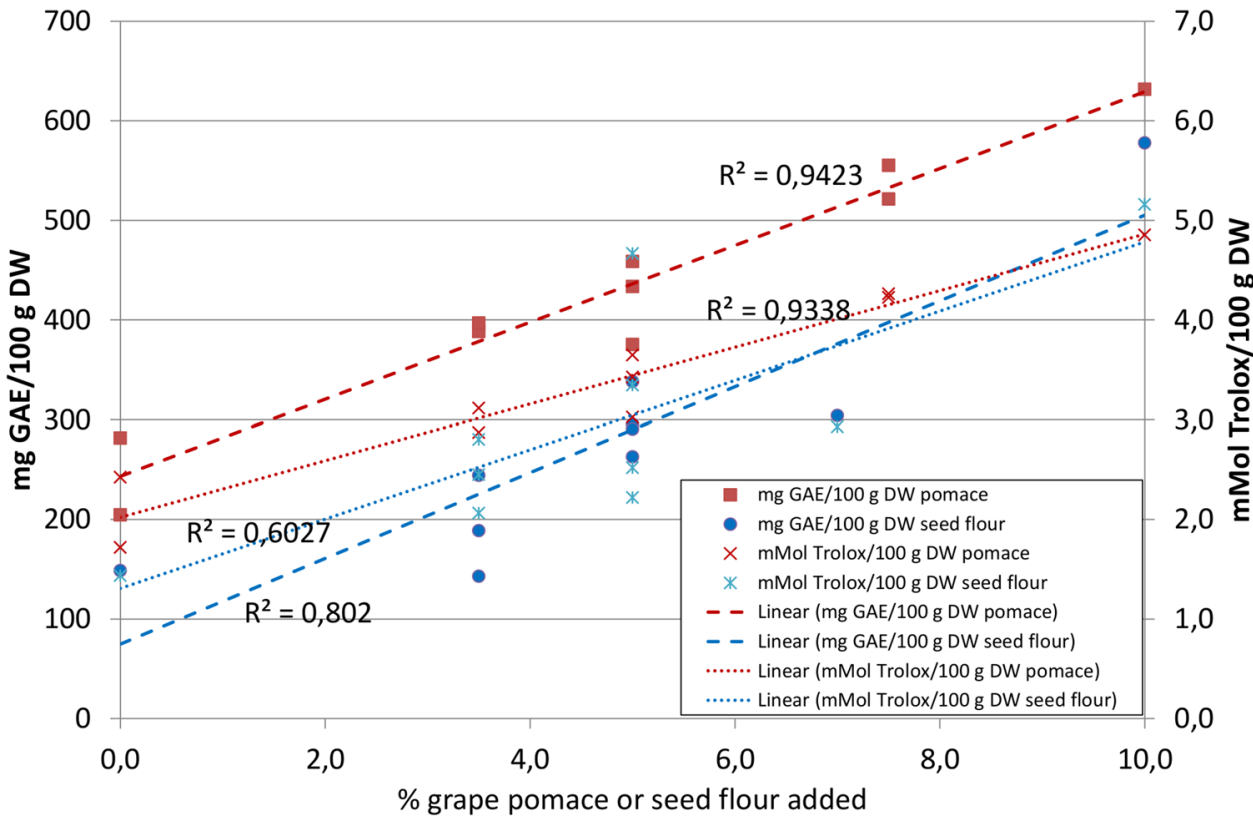

structure. In a previous project other fibrous material had been tested as chocolate ingredients without extra grinding, which resulted in unacceptable products [39]. It had been shown by Meier et al. [40] that other products like muesli bars or bread sticks are still acceptable when incorporating coarsely ground grape pomace. Chocolate seems to be a more delicate matrix, so in this study it was found that pre-grinding of the pure material is essential. To a certain extent this is possible by dry milling using, e.g., pin or disk mills. Wet grinding together with fat can result in particle sizes close to those expected for final chocolate. This might also be possible by dry fine milling technologies, e.g., a jet mill, which would be an interesting option for on-going development.

However, it seems to be the safer option to add the product in the beginning of the process, which gave more reliable results in this project. But if chocolate is made together with grape pomace, all devices must be cleaned laboriously, before other products could be made using the same equipment. So from the standpoint of flexibility and cleaning it seems an attractive option to produce a very fine-ground ingredient instead-like done here by wet grinding in a ball mill — and to add it to the final chocolate just before tempering and moulding.

Acknowledgments This project was sponsored by the Internal Research Program of Neubrandenburg University of Applied Sciences. Student thesis by Kerstin Nentwig, Joanna Kos, Marcel Strasser, Benjamin Harloff, Bashar Hayani and Muad Almanasra provided significant contributions to the paper. We would also like to thank all our sensory panellists, Dipl.-Ing. Rita Schäpe and Rolf Kretzschmar for their support. 
Funding Open Access funding enabled and organized by Projekt DEAL.

\section{Compliance with ethical standards}

\section{Conflict of interest None.}

Ethical approval All sensory procedures performed in this study involving human participants were in accordance with the ethical standards of Neubrandenburg University of Applied Sciences, Germany.

Compliance with ethics requirement This article does not contain any studies with human or animal subjects.

Open Access This article is licensed under a Creative Commons Attribution 4.0 International License, which permits use, sharing, adaptation, distribution and reproduction in any medium or format, as long as you give appropriate credit to the original author(s) and the source, provide a link to the Creative Commons licence, and indicate if changes were made. The images or other third party material in this article are included in the article's Creative Commons licence, unless indicated otherwise in a credit line to the material. If material is not included in the article's Creative Commons licence and your intended use is not permitted by statutory regulation or exceeds the permitted use, you will need to obtain permission directly from the copyright holder. To view a copy of this licence, visit http://creativecommons.org/licenses/by/4.0/.

\section{References}

1. Klöck G, Noke A (2008) Veredlungsprodukte aus ungenutzten stoffströmen, industrial ecology erfolgreiche Wege zu nachhaltigen industriellen systemen. Vieweg+Teubner, Wiesbaden, pp $88-96$

2. Sun AY, Simonyi A, Sun GY (2002) The "French Paradox" and beyond: neuroprotective effects of polyphenols. Free Radic Biol Med 32(4):314-318

3. Soto ML, Falqué E, Dominguez H (2015) Relevance of natural phenolics from grape and derivative products in the formulation of cosmetics. Cosmetics 2(3):259-276

4. Matissek R, Baltes W (2016) Lebensmittelchemie. Springer Verlag, Berlin

5. Machado NFL, Domínguez-Perles R (2017) Addressing facts and gaps in the phenolic chemistry of winery by-products. Molecules 22(2):286. https://doi.org/10.3390/molecules22020286

6. European Council Directive 2000/36/EG relating to cocoa and chocolate products intended for human consumption. Off J Eur Communities, 3.8.2000, L 197/19

7. Muhammad D, Saputro A, Rottiers H, Van de Walle D, Dewettinck K (2018) Physicochemical properties and antioxidant activities of chocolates enriched with engineered cinnamon nanoparticles. Eur Food Res Technol 244:1185-1202. https://doi.org/10.1007/s0021 7-018-3035-2

8. Dwyer K, Hosseinnian F, Rod M (2014) The market potential of grape waste alternatives. J Food Res 3(2):91-106

9. Bolenz S, Meier J, Schäpe R (2000) Milchschokoladen in Deutschland: Parameter, die die Verbraucherakzeptanz beeinflussen Teil 1+2. Zucker- und Süßwarenwirtschaft 53(9):270-274 (53(10):309-314)

10. Beckett ST (2009) Industrial chocolate manufacture and use. Wiley-Blackwell, Chichester
11. Afoakwa E, Paterson A, Fowler M (2007) Factors influencing rheological and textural qualities in chocolate-review. Trends Food Sci Technol 18(6):290-298

12. Franke K, Scheruhn E, Tscheuschner HD (2002) Influence of milk powder properties on flow behaviour of milk chocolate. Milchwissenschaft 57(9/10):535-539

13. Bolenz S, Manske A, Langer M (2014) Improvement of process parameters and evaluation of milk chocolates made by the new coarse conching process. Eur Food Res Technol 238:863-874. https://doi.org/10.1007/s00217-014-2165-4

14. Bolenz S, Manske A (2013) Impact of fat content during grinding on particle size distribution and flow properties of milk chocolate. Eur Food Res Technol 236:863-872. https://doi.org/10.1007/ s00217-013-1944-7

15. Bolenz $S$, Holm M, Langkrär C (2014) Improving particle size distribution and flow properties of milk chocolate produced by ball mill and blending. Eur Food Res Technol 238:139-147. https ://doi.org/10.1007/s00217-013-2094-7

16. Strasser M (2018) Optimierung einer Milchschokoladenrezeptur mit den Lebensmittelzusätzen Inulin und Traubentrester. Bachelor Thesis Neubrandenburg Univ. Appl. Sci

17. Ziegler GR, Langiotti JP (2003) Grinding spray-dried milk powder near the glass transition temperature. J Food Process Eng 26:149-160

18. Bolenz S, Amtsberg K, Lipp E (2005) New concept for fast continuous conching of milk chocolate. Eur Food Res Technol 220:47-54. https://doi.org/10.1007/s00217-004-1047-6

19. Kleinert J (1997) Handbuch der Kakaoverarbeitung und Schokoladeherstellung. Behr's Verlag, Hamburg

20. Aeschlimann JM, Beckett ST (2000) International inter-laboratory trials to determine the factors affecting the measurement of chocolate viscosity. J Texture Stud 31(5):541-576

21. Bolenz S, Tischer T (2013) Measuring shear stress at lowest possible shear rates and improving viscosity determination of fat suspensions, for example chocolates. Int J Food Sci Technol 48:2408-2416. https://doi.org/10.1111/ijfs.12232

22. Magalhães L, Segundo M, Reis S, Lima J (2008) Methodological aspects about in vitro evaluation of antioxidant properties. Anal Chim Acta 613(1):1-19

23. Paschke M (2012) Vergleich von Labormethoden zur Messung des antioxidativen Potentials von Pflanzenteilen. HS Neubrandenburg, Masterthesis

24. Wollgast J (2004) The contents and effects of polyphenols in chocolate. Dissertation, Justus-Liebig-Universität Gießen

25. Frankel EN, Meyer AS (2000) The problems of using one dimensional methods to evaluated multifunctional food and biological antioxidants. J Sci Food Agric 80:1925-1941

26. Guinard JX, Mazzucchelli R (1999) Effects of sugar and fat on the sensory properties of milk chocolate descriptive analysis and instrumental measurements. J Sci Food Agric 79:1331-1339

27. Derndorfer E (2016) Lebensmittelsensorik. Facultas, Wien

28. K Nentwig 2017 Coarse conched grape pomace chocolate: technological, nutritional and health aspects of polyphenols, grape seed oil and fibre Master Project Neubrandenburg Univ App Sci

29. Bolenz S (2018) Technological and nutritional aspects of milk chocolate enriched with grape pomace products. Poster at ZDS ChocoTec Cologne

30. Kos J (2018) Herstellung von schokolade mit traubentrester unter nutzung des grobconchier-verfahrens. Master Thesis Neubrandenburg Univ. App. Sci

31. Glöde L (2019) Weiterentwicklung des verfahrens zur herstellung einer milchschokolade unter verwendung von traubentrester. Master Thesis Neubrandenburg Univ. Appl. Sci

32. Almanasra M (2019) Technologische und analytische aspekte von traubenkernmehl- angereicherter milchschokolade. Master Thesis Neubrandenburg Univ. Appl. Sci 
33. Ziegler GR, Hogg R (2009) Particle size reduction. In: Beckett ST (ed) Industrial chocolate manufacture and use. WileyBlackwell, Chichester, pp 142-166

34. Miller KB, Stuart DA, Smith NL, Lee CY, McHale NL, Flanagan JA, Ou B, Hurst WJ (2006) Antioxidant activity and polyphenol and procyanidin contents of selected commercially available cocoa-containing and chocolate products in the United States. J Agric Food Chem 54:4062-4068. https://doi. org/10.1021/jf060290o

35. Höner K, Frerichs N (2007) Antioxidative capacity of different kinds of chocolate as a function of their cocoa content. Ernährungs Umschau 54:520-525

36. Maier T, Göppert A, Kammerer DR, Schieber A, Carle R (2008) Optimization of a process for enzyme-assisted pigment extraction from grape (Vitis vinifera L.) pomace. Eur Food Res Technol 227:267-275. https://doi.org/10.1007/s00217-007-0720-y

37. Carle R, Schieber A, Bitsch R, Netzel M (2007) Gewinnung von Traubentresterextrakten und untersuchungen zum nachweis ihrer funktionellen eigenschaften. Final Report AiF 14039 BG, FEI e.V. Bonn
38. Netzel M, Netzel G, Maier T, Kammerer DR, Carle R, Schieber A, Bitsch I, Bitsch R (2008) Polyphenole aus trauben-erste ergebnisse aus metabolisierungsstudien mit traubentresterextrakten und probanden. Flüssiges Obst 75:240-246

39. Bolenz S, Amtsberg K, Schäpe R (2006) Broader usage of sugars and fillers in milk chocolate according to the new EC cocoa directive. Int J Food Sci Technol 41(1):45-55. https://doi.org/10.111 1/j.1365-2621.2005.01023.x

40. Meier J, John T, Schmidt C (2003) Einsatzmöglichkeiten von Zutaten mit funktionellem Wirkstoffspektrum am Beispiel von Traubenschalenextraktionsrückständen. In: Vitamine und Zusatzstoffe in der Ernährung von Mensch und Tier. 9 Symposium Sept. 24./25. 2003, Jena/Thüringen, Bundesforschungsanstalt für Landwirtschaft (FAL), pp 88-93

Publisher's Note Springer Nature remains neutral with regard to jurisdictional claims in published maps and institutional affiliations. 